\title{
Impact of an open online course on the connectivist behaviours of Alaska teachers
}

\author{
Lee Graham and Virgil Fredenberg \\ University of Alaska Southeast, United States
}

\begin{abstract}
In this article we will describe a continuum of development towards knowledge generation and networked learning which emerges as practising teachers participate in a connectivist experience offered through an open online class (OOC) learning design. We believe that this design offers an opportunity to provide authentic professional development and collaboration particularly for those teachers in remote areas such as in the Alaska bush. Research remains in progress; however, current findings indicate that those teachers who valued the connectivist experience indicate a desire to promote these experiences with their own students. Content analysis of interviews, focus group transcripts and Twitter transcripts reveal four distinct stages of awareness of values necessary for success in the OOC. Of the practising teachers who enrolled, 98\% were successful in completing the OOC for credit; however, $20 \%$ remained resistant to connectivist pedagogy throughout the experience.
\end{abstract}

\section{Introduction}

Connectivism, defined by George Siemens (2004) as a learning theory for a digital age, asserts that networked knowledge changes the paradigm for meaning-making in fundamental ways. According to Siemens, connectivism is based on the following principles:

- $\quad$ Learning and knowledge rests in diversity of opinions.

- Learning is a process of connecting specialised nodes or information sources.

- Learning may reside in non-human appliances.

- Capacity to know more is more critical than what is currently known.

- Nurturing and maintaining connections is needed to facilitate continual learning.

- Ability to see connections between fields, ideas, and concepts is a core skill.

- Currency (accurate, up-to-date knowledge) is the intent of all connectivist learning activities

- Decision-making is itself a learning process. Choosing what to learn and the meaning of incoming information is seen through the lens of a shifting reality. While there is a right answer now, it may be wrong tomorrow due to alterations in the information climate affecting the decision. (Siemens, 2004, n.p.)

While connectivism has sparked a conversation and created interest in the manner in which learners acquire knowledge in distributed environments, its claim to being a theory is in question, and the validity of this claim remains to be seen. Those who oppose the view of connectivism as a theory do so on several broad grounds. First of all, it is purported that principles of connectivism do not meet the criteria for a learning theory and that other theories which currently exist are more appropriate to Web 2.0 learning experiences (Kop \& Hill, 2008). Lange (Talk:Connectivism, 2014) argues that connectivism brings no new considerations of learning to the discipline, and instead rehashes ideas already contained in other learning theories. Others argue that connectivism is a pedagogical approach, and, even from this pedagogical standpoint, question its relevance to current practice (Bell, 2011; Verhagen, 2006). Most critically, Clarà \& Barberà (2014) call for the rejection of connectivism as a theory or pedagogy and argue in favor of a Vygotskian tradition of cultural psychology, better suited to the Web 2.0 environment. We acknowledge these critiques of connectivism, and the often fierce debate which accompanies them.

However, habits of connectivism in concert with the development of the professional learning network (PLN) seem to hold a great deal of promise to assist teachers in maintaining relevant technological and pedagogical skills (Trust, 2012). If the principles of connectivism are embraced, and confidence in these ways of being are developed, it is possible that teachers will develop sufficient resources to expertly 
maintain technological knowledge and skills important to student success in quickly changing educational environments. (Andrawes, 2011; Ertmer \& Ottenbreit-Leftwich, 2010). Key to the development of this way of being is confidence to engage in risk-taking behaviours that will allow teachers to discern the technology software and skills they can immediately apply to their classrooms for their students' benefit (Rolfe, 2010).

The MOOC (massive, open online course) is a relatively new phenomenon. The term MOOC was coined by Dave Cormier in 2008 to describe an online course offered in the open both for credit and for free to any who wished to enroll (Fini, 2009). The connectivist MOOC as envisioned by McAuley, Stewart Siemens, and Cormier (2010) is presented as an approach which can prepare students for participation in a knowledge economy (Powell \& Snellman, 2004). Powell and Snellman note that accelerating rates of technological and scientific advancement as well as rapid obsolescence are effects of the knowledge economy. While the course we explore was designed around this framework, the massive aspect of the course did not materialise in the semester in which the course was offered. Therefore, we frame this course not as a MOOC, but as an open online course (OOC), less the massive. We posit that teachers have a responsibility to model mastery of adaptability to a knowledge economy. We believe developing and maintaining relationships and generating and sharing knowledge with professional networks are crucial aspects of effective adaptation to a knowledge economy. We chose to use the principles of connectivism as a framework for the course not because we believed it was a theory or because we wished to argue its value as pedagogy. Our intent was to apply these principles, which we see as integral skills for informal learning and adaptation to new and emerging technology, to the learning our students would encounter.

The researchers approached the OOC with differing motivation and pedagogical approaches. Each researcher engaged in on-ground education at a state university as they completed their terminal degree. Researcher 1 comes from an educational technology perspective; researcher 2 is a professor of math education; and researcher 3 has an extensive education in science and science education. All researchers have experience teaching online courses with 16 years, 10 years and seven years of experience respectively. Researcher 1 approached the design of the OOC from an educational technology perspective, with a great interest in authentic creation of ongoing professional development networks which would sustain practising teachers beyond the bounded classroom environment. Researcher 2 approached the design of the OOC from a pedagogical perspective, seeking to further develop learner autonomy and student-centred experiences in the open environment. Researcher 3 approached the design of the OOC as an experience which would provide new approaches to online teaching and learning particularly in open environments. He wanted to learn the pedagogy and explore how he might use it in his own online instruction.

As college professors and researchers, we have historically been social constructivist oriented. We suspect that the connectivist MOOC as envisioned by McAuley et al. (2010) offers a unique framework for students to gain essential knowledge and skills necessary for facing the challenges of a rapidly changing technical and pedagogical landscape inherent in a knowledge economy. The classroom teachers participating in the OOC practise in urban or rural and remote areas of Alaska. Many function in very small schools and are isolated from other teachers and education professionals, limiting their ability to physically collaborate and share with a larger group. The establishment of a PLN as an explicit byproduct of the OOC could help these teachers to create relationships which would assist them in ongoing professional development despite their often remote rural settings (Mackey \& Evans, 2011; Tuck, 2009).

\section{Methodology}

Because we were so deeply involved in both the design and the implementation of the \#diffimooc, we took a participatory action research approach to the study (Kidd \& Kral, 2005). Participatory action research is a collaborative approach to research through data triangulation and ongoing review and reflection by participants to create a framework for organizational change. The change we collectively seek to effect is in the preparation of Advanced Teacher candidates to maintain relevance and resilience in a quickly changing technological environment.

Data collection consisted of the distribution of questionnaires in Week Two and Week Five of the course. Results of these surveys were used to inform changes in the planned activities and design of the course. In 
the final week, a survey was administered to collect data for the use of informing future design (Copies of the survey questions can be requested from the authors). In addition, the researchers found it necessary to speak individually or in groups with teachers to allow them to voice their opinions and preferences. Ultimately, synchronous meetings in WebEx were scheduled to assist those who felt they needed more guidance. These meetings served as tools for feedback as well as an instructional venue. Finally, an unstructured focus group was held at the end of the experience to gain feedback and teacher suggestions. Transcripts from these meetings were triangulated with survey results and student Twitter sessions from Weeks Two, Five and Seven of the course to identify themes in the data.

The results of the research were reviewed by teachers in the class who served as members of a validation group, and the researchers conducting the study served as critical friends to each other throughout the study (McNiff \& Whitehead, 2005). In addition, initial research findings were presented at the Alaska Society for Technology in Education Conference (2013) as well as to faculty members at the University of Alaska Southeast (iLearn, 2013) for feedback and critique.

\section{Preparing the OOC}

We began research and curriculum design for the OOC in Fall, 2012. Over a 4-month period of time, we met approximately twice per week for an average of an hour per meeting. We discussed the research that had been done to date, possible structures for the class, and the background knowledge of the teachers who would be in our classes. The \#diffimooc was designed as a connectivist and open experience. The content of the course focused on Differentiating Instruction through Technology, and we believed that the a connectivist format would allow us to model differentiation in a social networked environment, as well as provide teachers with experiences authentic to their own classroom environments. Those enrolled in a Master of Educational Technology or the endorsement program in K-8 Math instruction were enrolled in the experience for credit, and made up the core group of participants.

This graduate experience was offered to three cohorts of graduate students enrolled in Master of Education programs at the University of Alaska Southeast. Students enrolled for credit were 35 practising teachers across Alaska and one information technology professional. Of the 35 enrolled teachers, 34 completed the experience. In addition, 28 individuals signed up for the OOC as a free experience. Of these 28, only one selected to complete the course. Finally, one additional teacher selected to join and complete this experience for the purpose of gaining Professional Education Credit.

We designed this experience to take place in three phases, over 15 weeks. Each phase (which might be completed separately) consisted of 4 weeks of guided interaction. A 1-week orientation was offered to participants at the beginning of each phase of the course, and a final week was included for those taking the course for credit, so that they might present their final products.

In order to ensure that classroom learning would be shared, we decided that blogs would be the primary documentation of learning in the course. Teachers added their blog addresses to a Google Sheet so that it might be available to all those enrolled. In addition, they were provided information about adding classroom blogs to Google Reader for ease of access and following. While we had access to Blackboard, and knew that teachers would initially enter the course through this venue, we created a web page at http://www.diffimooc.com to house course materials. It was important to the group that the resources and activities were open so that anyone who wished to engage in the OOC, whether at the time it was being offered or later, might have that opportunity.

We subscribed to "the criticality of creation" in the OOC experience as identified by McAuley et al. (2010), who state "Creating a digital artifact helps learners to re-centre the course discussion to a more personal basis" (p. 28). Therefore, we organised the class around collaboration towards the creation of three large products, and ongoing knowledge creation and sharing via blogs and Twitter. Tutorials to assist teachers in creating screencasts and contributing to wikis were shared. In addition, we wished to prepare the teachers for the challenge of organising the massive amount of information they might encounter and find important to the course content. Therefore, we included suggestions that teachers use online bookmarking tools such as Diigo or Delicious. 
In the interests of usability and clarity, teachers were presented with a step-by-step suggestion of the way to approach the first week of the course. In addition, while no specific blogging tools, bookmarking tools, or video creation/sharing tools were recommended, it was required, for those taking the course for graduate credit, that teachers set up a blog, share their bookmarks, create a video introduction (with a video creation tool or with Xtranormal) and sign into Twitter the first week. As the OOC continued, each week, these teachers participated with their PLN as they blogged, created self-selected and designed group projects, and engaged in Twitter "focused chats".

A unique issue encountered as a result of offering this OOC for credit was the need to document the performance of teachers taking the course for credit in order to meet the requirements of accreditation bodies. In order to capture and assess student performance for accreditation requirements, the researchers chose to utilise LiveText (https://www.livetext.com/). LiveText is a portfolio management system used by many schools of education to collect data for assessment plans, and to aggregate this data for program improvement. Teachers enrolled in the OOC for credit gained access to LiveText, and submitted the URL for their blogs at the end of each week for assessment. In keeping with the spirit of the connectivist OOC, a process rubric was used during the weeks of the course that involved student collaboration and discussion towards creation of a product. In essence, if teachers participated with the PLN, the standard was met or met with strength, depending on the level and quality of the participation. The products submitted to LiveText were assessed with rubrics evaluating quality. Standards guiding the rubrics were from the National Educational Technology Standards for Teachers (NETS-T, 2008) and the National Educational Technology Standards for Coaches (NETS-C, 2011).

\section{Presence}

We struggled with what our presence would look like in the context of the OOC. While we realised that instructor presence was highly important, we also wanted to decrease dependence on the instructor, and encourage the development of like-minded networked learners. Because there were three of us, each teaching a separate section of the course, responsibilities could be divvied out accordingly. Researcher 1 took responsibility for coordinating the posting of the assignments. The assignments might be actually created by any of the three professors, and we recorded asynchronous video to provide teachers with a feeling of instructor presence and basic guidance.

Each instructor was responsible for facilitation of a 1-hour Twitter focus session each week, and teachers were encouraged to attend at least one of these focus sessions. We created this backchannel discussion for several reasons. First of all, it would allow us to, as much as was possible, keep a bit of a finger on the pulse of the class. It would provide us with a record of interaction and student sentiment and issues each week. We were uncomfortable with giving up all contact with the teachers and only communicating via the blogs. We felt that teachers needed exposure to multiple channels of communication, and that Twitter might be an anchor. Indeed, according to the end of the class survey, Twitter was ranked as the third most useful tool, with only blogs and email being more important to class success. In the focus group at the end of the experience, several teachers identified Twitter as "social hour" or "an online cocktail party". Ultimately, the researchers (and several teachers) attended Twitter sessions more than once per week in order to take part in the discussion, the relationship building and the camaraderie that was formed through the channel. However, not all teachers saw value in Twitter, and several still reported that they "just didn't get it" at the end of the course.

We provided scores to teachers each week in LiveText so that they might have ongoing feedback about their performance. This provided a private communication channel between teachers and the researchers. Feedback was process-focused but based on NETS-C and NETS-T standards for networked communication and contribution to the global community.

We felt that it would be important to provide teachers with a daily summary of postings to the Twitter feed. We called this summary "The Daily". The Daily was auto-generated each day from Paper.li, and was based on the \#diffimooc channel. We posted the link to The Daily on the Twitter feed each day.

We maintained presence on Twitter in order to monitor the feed and try to answer questions if they were presented. We responded to emails from those enrolled in the course immediately, and we communicated with them via Skype, via Google Hangouts, and via phone as we were contacted with questions. We 
acknowledge that this would not have been possible had the massive aspect of our OOC been realised; however, because the number of participants was manageable, we did provide this support and emphasised connectivist pedagogy over the crowdsourced knowledge. We urged teachers to network with each other, and tried to instill confidence in those learners who felt they needed instructor guidance.

Finally, it became obvious that some learners felt that they needed more assistance than we could provide in 140 character responses. We hosted four synchronous WebEx meetings of 1 hour each to respond to questions and to provide just-in-time tutorials. The WebEx meetings met the needs of those who felt that they didn’t understand assignments or who needed specific questions addressed.

\section{Findings}

We analysed responses to the final surveys in the course and triangulated these responses with earlier surveys, focus group and Twitter data to identify themes related to student development of connectivist practices. The benchmarks and indicators for student development identified along this continuum were defined from the highest level of adoption of connectivist practice to the lowest as master, emerging, awareness and resistance.

Master: Statements which reflected the values that we hoped learners would develop as a result of the OOC were coded as master. They reflect an acknowledgement of the value of diverse opinions and demonstrate an ability to discern elements of importance which present as a result of this diversity. The statements demonstrate an awareness that knowledge is fluid and changing, but also reflect empowerment in the face of this awareness. In addition, they demonstrate the understanding that the learner is responsible for being active in seeking and creating understanding with and from technology. Responses indicate confidence in authentic knowledge creation and demonstrate that the student values ongoing professional growth. Finally, the statements indicate an ability to generate new knowledge and willingness to share this knowledge with a network.

The majority of responses from learners in the OOC fall into the master category. Advice that participants at this level might give another teacher enrolled in this experience included discerning the important tools for success in the OOC, and resisting the idea that all tools encountered over the period of the OOC must be learned and fully mastered. These responses also indicate a high level of interaction, creation, and sharing with the PLN, and an intention to continue these activities as a part of professional practice.

Emerging: The statements indicating emerging practice in connectivist learning demonstrate awareness that knowledge is fluid and is changing, but do not indicate the identification of specific strategies for ongoing independent professional development. Risk-taking and fearlessness is expressed; however, there is a lack of criticality in terms of the tools, the strategies and the path for ongoing professional growth. The network is valued, but is primarily seen as a resource for information and is represented in terms of blogs, videos and Twitter feeds rather than people who are sources of information. The comments do not indicate value attributed to personal knowledge generation or contribution to the greater professional community.

The statements made at this level demonstrate great promise towards facilitating independent professional development through the location of resources. In addition, these statements demonstrate confidence that the resources are an authentic and important aspect of the ongoing professional development plan. There is a lack of clear focus, however, on the knowledge path being pursued. Statements made in this category would indicate that others "try everything out" as opposed to the Master statements which recommended a more critical approach to the tools. Statements indicate exploration and developing strengths towards transferable skills and pedagogical technological understanding.

Awareness: The statements indicating an awareness of practice in connectivist learning demonstrate benefits derived from the course materials, and express that the course was valued as a bounded learning experience. These statements indicate familiarity with tools and increased proficiency in social learning environments as a result of the course, but do not acknowledge the importance of this learning to ongoing professional development or to skills enhancement. Rather than demonstrating an awareness that the course is a stepping stone to ongoing skills development, the statements demonstrate a satisfaction with 
the knowledge taken from the course. The network is seen as helpful in this instance, but not helpful beyond course completion or the development of the static skills targeted by the course.

These statements centred around the learning that occurred in the bounded environment as a finite experience with a firm beginning and ending date. Rather than looking forward to future skills or pedagogy that might be learned, the statements remain firmly focused on the learning that has occurred. The importance of the PLN is not mentioned or is negated in these statements. There is no doubt that learners who made these statements felt they benefitted from the course; however, the extended benefits we hoped would result from the OOC format were not evidenced in the comments.

Resistance: The statements demonstrating resistance to practice in connectivist Learning expressed outright anger or indignation at the pedagogy utilised in the OOC. These statements were disparaging of the learning experience, the instructional strategies, and the tools encountered. These statements indicated that learners may have actually experienced the network as a negative environment. Statements made in this category sometimes indicate a lack of comfort with technology as demonstrated by frustration with multiple passwords, multiple websites, and multiple online tools used in the open environment. However, some statements indicate that the student has a high level of technological expertise, and regardless of this comfort, experienced the OOC as substandard, chaotic, intrusive, and at times, offensive.

We might analyse this reaction to the experience through the lens of Piaget's concept of disequilibrium. As new knowledge is obtained, a state of disequilibrium may result and until the new knowledge is appropriately categorised in the schema frustration and anger can occur. Generally - if the task is within the scope of the student's capability - the student performs the task, gains the knowledge, accepts the understanding and regains a sense of equilibrium. The emotional state is then quelled (McLeod, 2009). Over the 15-week course, several participants never left the stage of disequilibrium. Learners performed the tasks required, received good marks in the class, but remained upset with the pedagogy of the course. These statements indicate a belief that learners had been left to do things on their own, that instructions were not clear and the design of the class was faulty, and that there was a need to go back frequently to course resources and directly and frequently contact instructors when obstacles were faced.

\section{Discussion}

In validation groups, we explored the stages which were identified, and the differences between performance at each of these stages - including possible reasons for these differences. Our explanation for the apparent confusion and chaos during the first week of the course was quite common sense and intuitive: This is a new and unfamiliar pedagogical framework and therefore it was met with confusion. Teachers signed up for the experience with expectations that they were taking an online course, but their experiences with online courses differed. Because of the newness of the paradigm, no student signed up with the expectation that they would be participating in fully open and networked learning. Therefore, in the first week of the experience, all participants were overwhelmed.

We realised that learners who demonstrated characteristics of the master were by and large educational technology majors or participants who had several experiences in their program which (inadvertently) created the preparation for an entirely open and connected environment. While they weren't expecting open and connected learning, they still had an expectation that they would be required to make choices, create and share with colleagues, and self-regulate within the online environment. These teachers also had some familiarity with several of the tools used in the OOC, although few had familiarity with all of the tools used to connect.

These learners demonstrated autonomy and a willingness to delve into the work of others in order to gain and make meaning in the class. One student shared, "I may use [my PLN] for support if I have questions. I may just spend some time reading blogs I have missed. I learned a great deal from reading the blogs.” The ability to locate, read and make meaning from the blogs, as well as contribute to the blogs of others was a high indicator of both master and emerging practice in connectivism. These teachers indicated that they valued their experience and felt that it was one they wished to share with their own classroom students. One teacher shared that her goal, now that the OOC was over, was "finding more ways for my students to connect and to explore and create on their own.” This statement and others like it indicated 
that the learning experience was worthwhile and that teachers who completed the experience viewed this pedagogy as important to the learning of their students.

We also realised early in the class that teachers who were resistant to the experience expected a synchronous online experience with Elluminate Live through Blackboard. They were overwhelmed and extremely frustrated with the new paradigm. Some comparison of student responses also indicated that teachers who were resistant had not taken asynchronous online courses in the past. They were unfamiliar with even a more traditional paradigm of asynchronous and student-centred learning; therefore, being plunged into an entirely open online environment with unfamiliar technology tools was disorienting and created confusion that some overcame, while many retained throughout the course. Because of the cognitive load issues (Sweller, Ayres, \& Kalyuga, 2011) with a new paradigm, new tools, new forms of learning, self-regulation and the content of the course, these teachers were not able to maintain equilibrium, and struggled throughout. Elluminate sessions were held for these teachers each week during the first weeks of the class. These meetings indicated a great desire for direct instruction and specific verbal direction.

To be fair, we did attempt to familiarise teachers with the new paradigm they would encounter in the OOC during the first week of the class. While this information did make a difference to a number of teachers in the class, and even sparked enthusiasm in some, for those teachers who presented as resistant the content seemed to have been lost in the struggle to sign up for new and unfamiliar services which this population of learners did not desire, and felt they did not need.

We underestimated the number of teachers participating in the class who would have neither Google accounts (for Google Groups); Blogger, WordPress or Weebly; Diigo, Delicious or Pinterest; or Twitter. Those teachers who presented comments at the awareness and resistant levels were entirely new to at least three of these means of networking and often were new to all four. In an attempt to assist learners in curating information (through Diigo, Delicious or Pinterest) we created a stressor. In an attempt to assist learners in making initial connections through Google Groups, we created a further stressor. And as we assisted (we believed) learners in using Google Reader to organise their blogs, we created yet another stressor. The same would be true of Wikispaces for group work, Twitter for social hour or content sharing, and any number of additional tools we might suggest to help organise the information abundance of the OOC. Our intention was to introduce teachers to a handful of tools at the beginning of the experience that that they might, if they wished, use throughout the class; however, this well-intentioned gesture became a possibly unnecessary source of chaos for the learner resistant to connectivist practices.

The statements coded as resistant also demonstrate a struggle with the role of the instructor in the OOC. Many of these statements indicated a need to be told what to do by the professor, or by other colleagues. For instance one student stated, "I didn't develop a PLN - assigned to a group who never contacted me when I tried to get help. Embarrassing.” Because teachers were asked to self-select their groups based on relationships formed in the first weeks of the class, it was difficult to account for the idea that the student was "assigned" to a group; however, if we consider this statement from the perspective of the learner who views the instructor as the centre of the learning process we may draw some conclusions. Initially, teachers were asked to introduce themselves in a Google Group, so that they might begin to get to know each other and decide who shared common goals with them. Google Groups were divided into grades taught, disciplines and interests. Participants might select the group that most reflected their own goals for the OOC. Ultimately, this information would help participants choose who they would like to work with. Learners with a more teacher-centred perspective may have assumed that this initial introduction in the Google Groups (from which most moved to their own self-selected and preferred networking tools including wikis, Wiggio, Edmodo, Google Hangouts and Google Sites) was actually the assignment to the group. This being the case, when the group disappeared in Week Three, re-formed into self-selected clusters, and began work in the wiki or in their preferred networking tools this student may have felt that the group was not responsive or had disappeared. Because the student wasn't comfortable with or could not make sense of the Twitter feed, and if the student had not mastered either going to the blogroll or going to Google Reader to follow the blogs, the student would not realise that the group had gone in its own direction. There was also a lack of awareness in these responses concerning the importance of the blogs of others as a tool for making sense of the course. These learners may have believed that short of instructor intervention, there was no recourse for meaning-making. 


\section{Conclusions}

Our intent was to explore the impact of the connectivist environment in the form of a OOC on the learning experience of in-service teachers and education professionals taking a course for credit. We found that by starting with seminal connectivist documents and designing from this philosophy, we created a great deal of chaos, unmanageable by teachers who did not have the technology skills to manage multiple log-ins, self-organise materials, and track several different communication forums. These teachers ultimately required scaffolding through synchronous meetings and one-to-one support from the professors teaching the class. These teachers made up approximately $40 \%$ of the student population of the OOC.

However, those teachers who did possess the skills necessary to manage multiple log-ins, use social bookmarking tools, self-organise materials and track several different communication forums, benefitted from the open learning experience and gained skills which they indicated would enhance their professional practice in an ongoing manner. They also expressed interest in engaging their own students in this form of learning.

The evolving stages of learning in an open online environment may serve to inform teachers or to assist them in self-selecting whether an online open environment is the best choice for their learning experience. Certainly an ongoing tolerance for ambiguity is necessary in order to engage in this experience, as is an ability to set goals, to filter out unnecessary materials and to organise helpful materials, resources, and connections which might assist in meeting individual goals.

Perhaps the most striking conclusion that we drew as a result of this experience was that the digital divide as we experienced it is not about infrastructure, hardware or connectivity. Those who participated in this experience had equal access to the information being shared. The digital divide that we saw in our course was defined by an individual's willingness and ability to manage multiple communication mediums and to organise and prioritise tasks and information in order to meet personal or group goals. Those teachers who possessed these skills and dispositions indicated that they benefitted from this experience, and would continue to engage in the collective for the purpose of ongoing learning. Those who did not, indicated they wished they had taken a different class, and expressed a desire to avoid the open environment.

As educators move forward in open environments, we would recommend ensuring that teachers who will, as a part of their program, engage in an open learning environment have at least one traditional asynchronous course as a prerequisite, in order to assist them in understanding the nature of asynchronous learning. We would also recommend that intentional scaffolding be provided to teachers as they engage in an open online experience. The introduction of two tools in the first week, with an emphasis on the need to "play" with these tools (as opposed to what may be perceived as high-risk activities related to the tools) could well allow teachers to experience more success with the open online experience. , We would recommend to school leaders that teachers be provided ongoing professional development in managing social media in their profession. Finally we recommend that school superintendents and principals promote ongoing engagement in a PLN by emphasizing its value through the teacher evaluation process.

We maintain that in rural and isolated environments, the OOC framework provides more benefits than risks. According to one member of the OOC, in her building "There's only one other math teacher, \& everyone else pretty much does their own thing." For isolated teachers such as this, connecting with a PLN could reasonably be the difference between professional growth and stagnation.

We continue to offer courses in this format to the educators in our master's programs. As we move forward we act upon the lessons we have learned. Despite the obstacles, we are quite pleased with some of the long-term benefits gained from this format, and we continue to assist the resistant in gaining understanding and skills which may ultimately lead to the development of their own PLN. 


\section{References}

Andrawes, T. (2011). Suggested educational competencies for school teachers in light of the global tendencies towards a knowledge economy. International Forum of Teaching \& Studies, 7(1), 30-58.

Bell, F. (2011). Connectivism: Its place in theory-informed research and innovation in technologyenabled learning. International Review of Research in Open and Distance Learning, 12(3), 98-118. Retrieved from http://www.irrodl.org/index.php/irrodl

Clarà, M., \& Barberà, E. (2014). Three problems with the connectivist conception of learning. Journal of Computer Assisted Learning, 30(3), 197-206. http://dx.doi.org/10.1111/jcal.12040

Ertmer, P., \& Ottenbreit-Leftwich, A. (2010). Teacher technology change: How knowledge, confidence, beliefs, and culture intersect. Journal of Research on Technology in Education, 42(3), 255-284. http://dx.doi.org/10.1080/15391523.2010.10782551

Fini, A. (2009). The technological dimension of a Massive Open Online Course: The case of the CCK08 course tools. International Review of Research in Open and Distance Learning, 10(5). Retrieved from http://www.irrodl.org/index.php/irrodl

Kidd, S., \& Kral, M. (2005). Practicing participatory action research. Journal of Counseling Psychology, 52(2), 187-195. http://dx.doi.org/10.1037/0022-0167.52.2.187

Kop, R., \& Hill, A. (2008). Connectivism: Learning theory of the future or vestige of the past?. International Review of Research in Open and Distance Learning, 9(3). Retrieved from http://www.irrodl.org/index.php/irrodl

Mackey, J., \& Evans, T. (2011). Interconnecting networks of practice for professional learning. International Review of Research in Open and Distance Learning, 12(3), 1-18. Retrieved from http://www.irrodl.org/index.php/irrodl

McAuley A., Stewart B., Siemens, G. \& Cormier, D. (2010). The MOOC model for digital practice. Retrieved from https://oerknowledgecloud.org/sites/oerknowledgecloud.org/files/MOOC_Final_0.pdf

McLeod, S. A. (2009). Jean Piaget. Simply Psychology. Retrieved from http://www.simplypsychology.org/piaget.html

McNiff, J., \& Whitehead, J. (2005). All you need to know about action research. London: Sage.

National Educational Technology Standards for Coaches. (2011). Retrieved from http://www.iste.org/docs/pdfs/nets-c.pdf?sfvrsn=2

National Educational Technology Standards for Teachers. (2008). Retrieved from http://www.iste.org/docs/pdfs/nets-t-standards.pdf?sfvrsn=2

Powell W., \& Snellman K. (2004). The knowledge economy. Annual Review of Sociology, 30, 199-220. http://dx.doi.org/10.1146/annurev.soc.29.010202.100037

Rolfe, H. (2010). Learning to take risks, learning to succeed. London: National Endowment for Science, Technology and the Arts. Retrieved from http://www.nesta.org.uk/library/documents/Learning to take_risks.pdf

Siemens, G. (2004, December 12). Connectivism: A learning theory for the digital age [Blog post]. elearnspace. Retrieved from http://www.elearnspace.org/Articles/connectivism.htm

Sweller, J., Ayres, P., \& Kalyuga, S. (2011). Cognitive load theory (Vol. 1). Dordrecht: Springer.

Talk:Connectivism. (2014). In Wikipedia. Retrieved December 1, 2014, from http://en.wikipedia.org/wiki/Talk:Connectivism

Trust, T. (2012). Professional learning networks designed for teacher learning. Australian Educational Computing, 27(1), 34-38.

Tuck, A. (2009). Small school challenges: Learning lessons from small school headteachers [Report]. Nottingham: National College for School Leadership. Retrieved from http://dera.ioe.ac.uk/3752/1/download\%3Fid\%3D21849\%26filename\%3Dsmall-school-challenges.pdf

Verhagen, P. (2006). Connectivism: A new learning theory? Retrieved from http://www.scribd.com/doc/88324962/Connectivism-a-New-Learning-Theory

Whitby, T. (2013, July 8). Twitterati: Progressive EDU leaders or outliers? [Blog post]. My Island View. Retrieved from http://tomwhitby.wordpress.com/2013/07/08/Twitterati-progressive-edu-leaders-oroutliers/ 
Australasian Journal of Educational Technology, 2015, 31(2).

Corresponding author: Lee Graham, drlee.graham1@gmail.com

Australasian Journal of Educational Technology (c) 2015.

Please cite as: Graham, L., \& Fredenberg, V. (2015). Impact of an open online course on the connectivist behaviours of Alaska teachers. Australasian Journal of Educational Technology, 31(2), 140-149. 